\title{
A Cross-sectional study to assess reasons influencing unmet need for contraceptive choices among married women in rural field practice area
}

\author{
A Bhargavi ${ }^{1}, \mathrm{~K} \mathrm{Gangadhara} \mathrm{Reddy}^{2}, \mathrm{~A} \mathrm{H} \mathrm{Salgar}^{3}$
}

\begin{abstract}
${ }^{1}$ Assistant Professor, Department of Community Medicine, Kamineni Academy of Medical Sciences and Research Centre, Hyderabad, Telangana-500068, INDIA.

${ }^{2}$ Assistant Professor, Department of Community Medicine, Ayaan Institute Of Medical Sciences And Research Centre, Kankamandi, R.R.District,Telangana-501504, INDIA.

${ }^{3}$ Associate Professor, Department of Community Medicine, DVVPF's Medical College and Hospital, Ahmednagar, Maharashtra, INDIA. Email: bhargavianreddy@gmail.com, gangadharareddy89@gmail.com, aki salgar@yahoo.co.in
\end{abstract}

\begin{abstract}
Background: Unmet need is defined on the basis of survey data as the percentage of women who are currently not using any method of contraception and want no more child (limiting) or delay child bearing (spacing). ${ }^{3}$ The unmet need for family planning is declining but is still very high. There are various reasons responsible for unmet needs of family planning. Objective: To assess reasons influencing contraceptive method choices among women in rural field practice area. Methodology: The study was a cross sectional study among married women with reproductive age group in rural areas of Sangareddy district carried out in Department of Community Medicine, MNR Medical College, Sangareddy, (TS) during November 2015 to February 2016. A total sample size of 113 Women who are married in age group of 15-45 years and presumed to be sexually active were included in study. The data were collected using structured questionnaire and in depth interview guide in local language. The collected data were analyzed with proper statistical methods using MS excel 2010. Results: The utilization of contraceptive method was done by $52.21 \%$ women. The majority of the women not using contraception was because of refusal from husband (83.33\%) followed by fear about contraception $(77.78 \%)$ and religion beliefs (16.67\%) Conclusion: Hence, we conclude that health awareness should be created among women regarding importance of contraceptive method.

Keywords: Unmet need, Contraceptive, married women, rural.
\end{abstract}

\section{*Address for Correspondence:}

Dr Gangadhara Reddy, Assistant professor, Department of Community Medicine, Ayaan Institute of Medical Sciences and Research Centre, Kankamandi, R.R.District,Telangana-501504, INDIA.

Email: gangadharareddy89@gmail.com

Received Date: 02/11/2019 Revised Date: 13/12/2019 Accepted Date: 23/01/2020

DOI: https://doi.org/10.26611/10111531

This work is licensed under a Creative Commons Attribution-NonCommercial 4.0 International License. (cc)) EY-NC

\begin{tabular}{|l|l|}
\hline \multicolumn{2}{|c|}{ Access this article online } \\
\hline Quick Response Code: & Website: \\
\hline & www.medpulse.in \\
\hline
\end{tabular}

\section{INTRODUCTION}

An International Conference on Population and Development (ICPD), Cairo, 1994 and the fourth world conference on women, Beijing, 1995 emphasized women empowerment including reproductive and sexual rights as the basic tool for development. ${ }^{1}$ In developing countries an estimated 200 million couples would like to delay or stop childbearing but are not using any methods of family planning. ${ }^{2}$ Unmet need is defined on the basis of survey data as the percentage of women who are currently not using any method of contraception and want no more child (limiting) or delay child bearing (spacing). ${ }^{3}$ The unmet need for family planning is declining but is still very high. There are various reasons responsible for unmet needs of 
family planning according to World Health Organization (WHO) are ${ }^{2}$ limited choice of family planning methods, limited access to contraception mainly among young people, poor people or unmarried people, fear or experience of having side-effects, cultural or religious opposition and poor quality of available family planning services. The present study was undertaken on contraceptive method of choice and its influencing factors of women in rural field practice area of tertiary care center. OBJECTIVE:

- To assess reasons influencing contraceptive method choices among women in rural field practice area.

\section{METHODOLOGY}

The study was a cross sectional study among married women with reproductive age group in rural area of
Sangareddy district. The study was carried out in Department of Community Medicine, MNR Medical College, Sangareddy, (TS) during November 2015 to February 2016. A total sample size of 113 Women who are married in age group of 15-45 years and presumed to be sexually active were included in study. Unmarried and not willing to participate in study were excluded. The sample size for this study was calculated on the basis of total number of eligible couples. There were 1130 eligible couples in rural field practice area and $10 \%$ of that i.e. 113 were taken as sample size. The data were collected using structured questionnaire and in depth interview guide in local language. The questionnaire was used to collect information on use of contraceptives, personal, sociodemography and factors influencing contraceptive method choices. The collected data were analyzed with proper statistical methods using MS excel 2010.

\section{RESULTS}

\begin{tabular}{ccc}
\multicolumn{3}{c}{ Table 1: Distribution according to use of contraception } \\
\hline Contraception used & No. of women & Percentage \\
\hline Yes & $\mathbf{5 9}$ & $\mathbf{5 2 . 2 1}$ \\
No & $\mathbf{5 4}$ & $\mathbf{4 7 . 7 9}$ \\
\hline Total & 113 & 100 \\
\hline
\end{tabular}

It was seen that the utilization of contraceptive method was done by $52.21 \%$ women.

Table 2: Reasons influencing unmet need for choice of contraceptive method used among women

\begin{tabular}{ccc}
\hline Reasons influencing & No. of women $(\mathrm{n}=54))$ & Percentage \\
\hline Fear about contraception & 42 & 77.78 \\
Refusal husband / partner & 45 & 83.33 \\
Religion beliefs & 09 & 16.67 \\
Non availability of contraceptive methods & 07 & 12.96 \\
Inadequate financial support & 09 & 16.67 \\
\hline
\end{tabular}

(*Multiple response present)

It was observed that majority of the women not using contraception was because of refusal from husband $(83.33 \%)$ followed by fear about contraception (77.78\%) and religion beliefs (16.67\%)

\begin{tabular}{cccccc} 
Table 3: Association of use of contraception and reasons influencing among women: \\
\cline { 1 - 4 } Reasons influencing & & \multicolumn{2}{c}{ Use of contraception } & P value \\
\cline { 2 - 4 } & & Yes & No & \\
\hline Fear about contraception & Yes & 20 & 42 & $<0.0001^{*}$ \\
& No & 39 & 12 & \\
Refusal husband / partner & Yes & 29 & 45 & $<0.0001^{*}$ \\
& No & 30 & 09 & \\
Religion beliefs & Yes & 03 & 09 & 0.09 \\
& No & 56 & 45 & \\
Non availability of contraceptive methods & Yes & 01 & 07 & $0.02^{*}$ \\
& No & 58 & 47 & \\
Inadequate financial support & Yes & 04 & 09 & 0.17 \\
& No & 55 & 45 & \\
\hline
\end{tabular}

$\left({ }^{*} \mathrm{P}<0.05\right.$ statistically significant)

The association of use of contraception and reasons influencing unmet need for choice of contraceptive method used showed fear about contraception, refusal by husband and non availability showed statistical significant association. $(\mathrm{P}<0.05)$ 


\section{DISCUSSION}

The present cross sectional study was conducted among married women with reproductive age group in rural areas of Sangareddy district by Department of Community Medicine, MNR Medical College, Sangareddy, (TS). A total sample size of 113 Women who are married in age group of 15-45 years and presumed to be sexually active were included in study. In the present study, among 113 women of reproductive age group 54 (47.79\%) of women had unmet need for family planning. This is quite higher than that of national i.e. $12.9 \%$ and $12.1 \%$ as per NFHS $4 .{ }^{4}$ It was observed that majority of the women not using contraception was because of refusal from husband (83.33\%) followed by fear about contraception (77.78\%) and religion beliefs (16.67\%) Similar findings were reported by Paudel and Budhathoki ${ }^{5}$ Weeam S Hammoudeh $^{6}$ and Nisha Ram Relwani ${ }^{7}$. The association of use of contraception and reasons influencing unmet need for choice of contraceptive method used showed fear about contraception, refusal by husband and non availability showed statistical significant association. $\quad(\mathrm{P}<0.05)$ Opposition of husbands and in-laws to the practice also created a personal opposition among women which deterred them from adopting family planning methods. Similarly a study among Bengali women explained multiple reasons for not using any method and found opposition of family members, including husband as well, as an important cause ${ }^{8}$. The link between husband's approval and presence of mother-in-law in the household and lower uptake of contraception as seen in the work done by Pasha Omrana et al. ${ }^{9}$ among urban poor in Pakistan is explored and evidenced by various other studies ${ }^{10}$. Lack of knowledge/ignorance about family planning methods was also observed among Bengali women ${ }^{8}$ as one of the reasons affecting the practice. Education of women, exposure to media, concerted messages on family planning could help to overcome this barrier.

\section{CONCLUSION}

The study concludes that health awareness should be created among women regarding importance of contraceptive method.

\section{ACKNOWLEDGEMENTS}

Authors are thankful to all the faculty members of Dept. of Community Medicine for their support.

\section{REFERENCES}

1. Adhikari R, Soonthorndhada K, Prasartkul P. Correlates of unintended pregnancy among currently pregnant married women in Nepal. BMC Int Health Hum Rights. 2009 Aug 11;9:17.

2. World Health Organization. Family Planning. July 2012.

3. Bradley SEK, Croft TN, Fishel JD, Westoff CF. Revising Unmet Need for Family Planning: DHS Analytical Studies No. 25. Calverton, Maryland, USA: ICF International; 2012.

4. Bill and Melinda Gates Foundation. Family Planning Overview. 2018.

5. Paudel IS, Budhathoki SS. Unmet needs for family planning in Sunsari, eastern Nepal. Health Renaiss 2011;9(3):148-51

6. Weeam S Hammoudeh, Nirveen ME, Abu-Rmeileh. Factors associated with the use of family planning among Palestinian women. Paper presented at the IUSSP XXVI International Conference, 27 September 2009-2 Oct 2009, Marrakech, Morocco.2009.

7. Nisha Ram Relwani, Ajeet V Saoji, Meenal Kulkarni, Nandkishore Kasturwar, Ranjana Zade, Rishikesh Wadke. Revealing unmet need for contraception among married women in an urban slum of Nagpur. International Journal of Medical Science and Public Health. 2015; Vol 4:113640.

8. Sensarma, Pinaki and Bhaswati. Contraceptive use pattern and reasons for not using ontraception. Indian J Prev Soc Med, 2011; 42: 24-27.

9. Pasha Omrana, Fikree Fariyal F. and Sten Vermund. Determinants of unmet need for family planning in squatter settlements in Karachi, Pakistan. Asia Pac Popul J, 2001; 16: 93-108.

10. Stephenson, Rob and Hennink, Monique. Barriers to family planning use among the urban poor in Pakistan Popul J 2004;18:23-29.

Policy for Articles with Open Access:

Authors who publish with MedPulse International Journal of Community Medicine, Print ISSN: 2579-0862, Online ISSN: 2636-4743 agree to the following terms: Authors retain copyright and grant the journal right of first publication with the work simultaneously licensed under a Creative Commons Attribution License that allows others to share the work with an acknowledgement of the work's authorship and initial publication in this journal.

Authors are permitted and encouraged to post links to their work online (e.g., in institutional repositories or on their website) prior to and during the submission process, as it can lead to productive exchanges, as well as earlier and greater citation of published work. 